\title{
Varyans Analizỉ ve Tekrarlanan Ölçũmlũ Analiz Tekniklerinin I. Tip Hata Bakımından Karşılaştırılması
}

\author{
Ensar BAŞPINAR ${ }^{1}$ \\ Fikret GÜRBÜZ1 \\ Geliș Tarihi : 02.01.2001
}

Handan ÇAMDEVIREN ${ }^{2}$

\begin{abstract}
Ózet : Bu çalışmada, çeşitli grup sayısi-korelasyon katsayısı-örnek genişliğ kombinasyonlarında yer alan ölçum

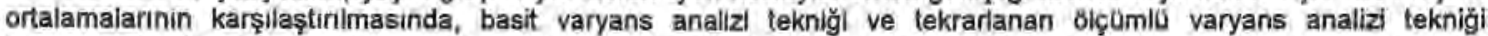
kullanilmıştır. Her bir kombinasyonda ampirik olarak gerçekleșen I. Tip hata yapma olasilıklari karșilaștirmali olarak incelenmiştir. Simulasyon çalışmasında, her grup sayısı-korelasyon katsayısı- örnek genişliği kombinasyonu için üretilen gözlem değerteri kullanilarak oluşturulan 100000 deneme ANOVA ve TÖVA teknikleri ile analiz edilmiş ve gerçekleşen 1. Tip hata olasılıkları hesaplanımıșłır. Gruplardaki gözlem değerleri arasında sıfırdan farkiı her korelasyon katsayısı için, ANOVA tekniği ile analiz etmenin bașlangı̨̧ta belirienen I. Tip hata olasılığında $(\alpha=0,05)$ onemil sapmalara sebep olduğu sonucuna varılmiștir.
\end{abstract}

Anahtar Kelimeler : Tekrarianan òiçŭm, varyans analizi, bağimilı göziemler, simülasyon, 1, Tip hata

\section{The Comparison of Analysis of Variance and Repeated Measurement Analysis Techniques for the Type I Error Rates}

\begin{abstract}
: in this sludy, simple analysis of variance and repeated measurement analysis techniques were used for comparison of means in different group number-correlation coefficient-sample size combinations. Probabilities of Type I error which were observed empirically, were investigated comparatively. In each group number- correlation coefficientsample size combinations were analyzed with the techniques of ANOVA and repeated measurement analysis and each simulation was repeated 100000 times. The probabilities of Type / error were calculated at the end of these analysis, As a result, ANOVA technique was used when the correlation coefficient among the observations in-groups was different from zero, nominal Type I error probability deviated significantly.
\end{abstract}

Key Words: Repeated measurements, analysis of variance, dependent observations, simulation, Type I error

\section{Giriş}

Fisher tarafindan geliștirilen varyans analizi tekniğ günümüzde yapılan bir çok araştırmanın istatistik olarak değerlendirilmesinde yaygın olarak kullanilmaktadir. Ancak, bu tekniğin uygulanabilmesi lçin bir takim ön sartların yerine getirilmesi gerekir (Düzounneş ve ark 1985 , Sokal ve Rohif 1995). Bunlarda birisi de, gózlemlerin bağımsızlığı on șartıdır. Gözlemlerin bağımsızlığı "farkı koşullarda elde edilen ölçüm değerlerinin farklı bireylere ait olması" şeklinde tanımlanabilir, Yani, ortalamaları karşılaştırılacak gruplardan eide edilen ölçamlerin, populasyondan tesadafen seçilen bireylere ait olmasıdir. Ancak, bazı araştırmalarda denemede kullanılacak birimlerin veya deney ünitelerinin yetersiz sayıda olmasi, denemenin daha hassas yapilma zorunluluğundan dolayı farklı koşullarda aynı bireylerin kullanılması veya deneme maliyetinin en aza indirilmesi gerekebilmektedir. Bunun yanı sıra, bazen de araștırmalarda deney anitelerinin uygulama öncesi ölçumleri kontrol grubu gibi dûşunălmektedir (kendi kontrollü denemeler). Bu gibi durumlarla karșılaşıldığında, aynı deney ünitelerinden birden fazla ölçăm değerlerinin alınması gerekir. Boylece karşılaștırılacak koşullardaki ölçümler, aynı bireylere ait olduğu için gözlemler bağımlı hale gelir. Bir başka deyişle aralarında bir korelasyon oluşur (Winer 1971). Bunun sonucu olarak da, gözlemlerin bağımsızlığı on şartı sağlanamamış olur. Bu on şartın yerine gelmediği durumlarda, basit varyans analizi tekniği kullanildığı zaman elde edilecek sonuçlarda gerçekleşen I. Tip hata yapma olasılıklarinin beklenenden az olacağı (Camdeviren 1995, Kurita 1996) tarafindan yapilan simülasyon çalıșmasinda bildirilmektedir. Ancak, gerçekleşen I. Tip hata yapma olasiliklarının farklı korelasyon dazeylerinden ne derece etkileneceğini onceden bilmek mamkun değildir: Bu çalışmada, bu koşullarda gerçekleşen I. Tip hatarın iyi bir tahmininin yapılması düşunülmüştür.

Bağımlı gözlemleri içeren en basit deneme dözenlerinin analizinde eş yapma t-testi (paired comparison t-test) yaygin bir şekilde kullanilmaktadir. Bu Tip deneme düzenlerinde, aynı deney unitelerinden aynı ozelliğe ilişkin iki farkı periyotta ölçam alınmakta ve bu periyotlarnn ortalamalan arasındaki fark değerlendirilmektedir. Aynı deney unitelerinden ikiden çok alçümùn elde edildiği deneme düzenlerinde ise, araștıncılar genellikle ikili eşler oluşturarak bu eşlerin ortalamalarını eş yapma t-testi ile karşılaştım aktadırlar. Bu durumun I. Tip hatayı artırdığı bilinmektedir

\footnotetext{
${ }_{1}^{1}$ Anikara Üniv. Ziraat Fak. Biyometri ve Genetik Anabilim Dali-Ankara

${ }^{2}$ Mersin Üniv. Tip Fak. Temel Tip Bilimleri Anabilim Dali, Blyoistatistik Bllim Dalı-Mersin
} 
(Garblz ve ark 1999). Bu deneme dozeninde verilenin analizinde yaygın olarak karşılaşılan en önemli problem. gởzlemlerin bağımsızlığı on şartının ihmal edilerek basit varyans analizi tekniği ile değerlendirilmesidir. Tekrarlanan ölçumla varyans analizi tekniğini uygulamalı bir şekilde tanitan Törkçe kaynak sayısınin yetersizliği ve buna bağlı olarak araștıricılann konu hakkındaki bilgilerinin sınirlı kalması, bu problemin başlıca sebebidir.

Bu çalışmada, çeşitti korelasyon-grup sayısı-örnek genişliği kombinasyonlarında elde edilen olçam ortalamalarının karşilaştırılmasında, basit varyans analizi tekniği (ANOVA) ve tekrarlanan ólçürnlú varyans analizi tekniğl (TÖVA) kullanılarak, her bir kombinasyonda ampirik olarak gerçekleşen I. Tip hata yapma olasillkları karşilaştormalı olarak incelenmiştir.

\section{Materyal ve Yontem}

Yapilan hipotez testlennde, gerçekleşen I. Tip hatalar, başlangiçta kararlaştinilan degerinden az veya fazla olabilmektedir. $H_{a}$ hipotezinin geçerli olduğu durumiarda l. Tip hatanin artmasi doğru karar vermiş oima olasılığını azaltmaktadir. I. Tip hatanin azalması ise II. Tip hatanin artmasina ve dolayli olarak testin gocunan daşmesine sébep olmaktadır. Hipotez testleri sonucunda verilen kararların güvenilirliği için gerçekleșen I. ve II. Tip hataların dengeli olması istenmektedir.(Wang 1971).

Bu çalışmada, çok değişkenli standart nomal dağılımdan [N(0,1)] simullasyonla çekilen gözlemler kullanılımıştır. Orneklerin alındığı populasyonlarda grup ortalamaları birbirine eşit olarak kabul edilmiştir $\left(\mu_{1}=\ldots=\mu_{j}=0\right)$. Ayrica gruplarda yer alan gozlemler arasındaki liş̦̌i yapisıni gơsteren karelasyon matrisleri ise grup sayısı-önek genişliği kombinasyonlarına göre aşağıdaki gibi iki farklı şekilde belirtenmiştir.

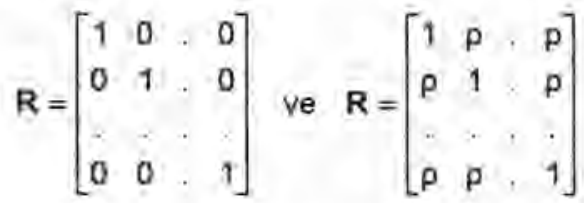

Bu matrisler incelendiğinde genel olarak iki farklı yapida korelasyon matrisi dusşünuldăğo görulär. Bu yapılardan birincisinde gruplardaki gózlemlerin bağımsız $\left(\rho_{i}=0\right)$ olduğu durum, ikincisinde ise gruplardaki gözlemlerin bağımlı olduğu durum ele alınmiştır. Simúlasyon çalıșmasında, grup sayısı, gruplardaki gözlem sayısı ve gruplardaki gözlemler arasındaki bağımilık derecesi dikkate alinarak doşünölen kombinasyoniar sırasıyla şoyledir. Grup sayıları, $k_{i}=2,3,4,5$ ve 10 , gruplardaki gözlem sayılarl; $n_{i}=5,10, \ldots, 30$; gruplardaki gözlemler arasındakj korelasyon katsayılan ise; $p_{i j}=0.0$. $0.10, \ldots, 0.90$, Denenen kombinasyonlarda butan gruplardaki gözlemler arasındaki korelasyon katsayılan birbirine eşit alınmıştır, Çalışmada sadece gruplardaki gözlem sayılarınin eşit olduğu durumlar incelenmiştir. Bu durumda doşūnälen toplam kombinasyon sayısı, 5 grup.
6 ornek genișliği ve 10 korelasyon katsayısı olmak uzere $5 \times 6 \times 10=300 \mathrm{dor}$.

Orneklerin, bilgisayar ortamında aretilmesinde ve simulasyon denemelerinin yarotölmesinde Microsoft Fortran Power Station 4.0 programlama dilinde yazilan programiar ve IMSL kütóphanesindeki alt-programlar kullanılmıştır. Çalışmada kullanılan her bir kombinasyon için 100000 simulasyon denemesi yapilmıştır. Bu 100000 simulasyon denemesinin her bírinde yapilan hipotez testlerinde, başlangıçta belirlenen I. Tip hata (yanima) olasılığı $(\alpha) 0.05$ olarak kararlaştırıldığında, her bir analiz tekniğine göre hesaplanan $F$ değeri lle $F$ tablo değeri karşılaştirilmiş ve bu karșilaştırma sonucu ret edilen hipotezler saydırilarak gerçekleşen I. Tip hata olasıliklar ampirik olarak hesaplanmiștir.

Çalışmada, bir çok araştırmada kullanilabileceğ daşanulerek grup sayıları, korelasyon katsayıları ve ornek genişlikleri uygulamada sıklikla karşilaşılabilecek seviyelerde ele alinarak grup sayisı-korelasyon katsayis|ornek genişliği kombinasyonları oluşturulmuştur.

Simulasyonia aretilen her bir deneme kombinasyonuna sırasıyla basit varyans analizi ve tekrarlanan ólçünlù varyans analizi tekniği uygulanmiş, analiz sonucunda gerçekleşen I. Tip hata yapma olasılıkları tablo haline getirilmiștir.

Varyans analizi tekniğinin uygulanması ile oluşturulan Varyans Analizi Tablosu ile tekrarianan olçümlü analiz tekniğinin uygulanmasi $\|_{e}$ oluş̧urulan Varyans Analizi Tablosu, her analliz tekniğinin istatistik modeli gereği farklı olup genellikle aşağıdaki gibi dúzenlenebilmektedirler (Çizelge 1.a ve b). Ancak, tekrarlanan ölçămiă analiz tekniğinde düzenlenen analiz tablosu, ele alinan faktor ve tekrarlanan olçam sayılanna göre çok çeșitli olabilmektedir. Bu çalışmada tek faktorla tekrarlanan blçămla deneme dözeni ele alınmıştir. Çônkó ancak bu dozen basit varyans analizi ile karșilaştırilabilmekțedir.

Çizelge 1, a. Varyans analizi tablosu

\begin{tabular}{|l|c|c|}
\hline Varyasyon kaynaği & $\begin{array}{c}\text { Serbestlik } \\
\text { derecesi }\end{array}$ & $\mathrm{E}(\mathrm{K}: 0)$ \\
\hline Genel & $k \mathrm{n}_{\mathrm{r}}-1$ & \\
\hline Gruplar arasi & $\mathrm{k}-1$ & $\sigma_{c}^{2}+n \sigma$ \\
\hline Hata & $k\left(\mathrm{n}_{-}-1\right)$ & $\sigma_{\tilde{\varepsilon}}^{2}$ \\
\hline
\end{tabular}

Cizelge 1.b. Tek faktörlì tekrarianan blçümlo deneme dózenine ilișin varyans analizi tablosu

\begin{tabular}{|l|l|l|}
\hline Varyasyon kaynagi & $\begin{array}{c}\text { Serbestilik } \\
\text { derecesi }\end{array}$ & $E(K: O)$ \\
\hline Genel & $n p-1$ & \\
\hline Denekler arasi & $n-1$ & $\sigma_{\varepsilon}^{2}+p 0$ \\
\hline Denekler ici & $n(p-1)$ & \\
\hline Periyotiar arast & $p-1$ & $\sigma_{\varepsilon}^{2}+n o$ \\
\hline Hata & $(n-1)(p-1)$ & $\sigma_{\varepsilon}^{2}$ \\
\hline
\end{tabular}




\section{Bulgular ve Tartışma}

Yapilan simblasyon çalişması sonucunda gerçekleşen I. Tip hatalara llişkin sonuçlar Cizelge 2 'de topluca verilmiştir. Çizelge 2 incelendiğinde grup sayilar $2,3,4,5$ ve 10 , her bir gruptaki gozlem sayiları $5,110,15,20,25,30$ ve gozlemler arasındaki korelasyoniar ise 0.0 ile 0.9 arasinda seçilmiștir Seçilen kombinasyonlarda pratikte yaygın bir şekilde kullanilan grup sayıları dikkate alınmıștır. Bunlara ilaveten, meveut olabilecek kotelasyon katsayılan için geniş bir aralık daşanalmuş̧tar.

Bu koşullarda basit varyans analizi tekniği ve tekrarlanan olçomlu varyans analizi teknlği uygulanarak gerçekleşen I. Tp hata olasiliklari hesaplanmiş ve ornekkerin alinmıș olduklan populasyoniann korelasyon katsayılarına göre aşağıdaki sonuçar elde edilmiştir.

1. Gozlemler birbirinden bağımsı, yani korelasyon katsayısı sıfir olduğunda, grup sayısı 2, 3, 4, 5 ve 10 ve gruplardaki gozlem sayilan da birbirine eșit ve $5,10,15$, 20,25 va 30 olarak doşunaldogönde, basit varyans analizi ve tekrarlanan olçamla varyans analizj tekniklerinde gerçekleșen 1. Tip hataların \% 5 civannda kaldiğı belirienmiştir (en dọşak 0.04944 , en boyok 0.05158

2. Gozlemier arasindaki korelasyonun artmasi sonucunda basit varyans analizi teknigi uygulandiğı zaman geçekleşen I. Tip hata yapma olasiliklaninda belirgin bir daşmenin olduğu göralmektedir. Bu doşme grup sayisi ve gruplardaki gözlem sayısı artikça artmaktadir. Mesela, 2 grupta gózlemier arasindaki korelasyon katsayısi 0.9 ve gruplarda 5 ' er gozlem mevout olduğu zaman gerçekleşen I. Tip hata yapma olasilığı $0.00060,15^{\prime}$ er gozlem olduğu zaman gerçekleşen hata 0.00001 ve 30 ' ar gózlem olduğu zaman gerçekleşen I. Tip hata 0.00000 (yeni, 100000 denemede $H_{0}$ hipotezi bir defa bile ret edilmemiştir. Olasılıkların 5 basamaklı verilmesinin sebebi de boyle durumlarda $H_{0}$ hipotezinin ką defa ret edildiğlni görebilmek içindir.) olarak bulunmuştur. Ayrica aynı koşullarda grup sayısı to olduğu zaman gerçekleşen I. Tip hata olasiliklari sirasiyla $0.00007,0.00000$ ve 0.00000 olarak bulunmuştur. Bu sonuçlara gore farklı gruplarda yer alan gozlemier arasında bir bağimlinğın yani korelasyonun mevcut olmasinin gerçekleşen I. Tip hata olasıliklarında onemli dazeyde doşmeye sebep olduğu soylenebilir.

Bu dosmeye grup sayısi ve gruplardaki güzlem sayılarının da etkisi vardır. Ancak gerçekleşen I. Tip hata yapma olasiliklarindaki değişmeye en etkili unsur gozlemler arasindaki korelasyon katsayısidir. Tekrarlanan olçămia varyans analizi tekniğinde ise, grup sayisipopulasyondaki korelasyon katsayısı-ornek genişliği kombinasyonlaninan hemen tamaminda gerçekleșen I. Tip hata olasilığı, pratik olarak bașlangıçta karariaștırılan \%5 kadardır. Simólasyon çalişmalarında gerçekleşen I. Tip hata olasiliklarınin \%4.0 $\mathrm{lle} \% 6.5$ arasında olması halinde bile bunlen $\% 5$ olarak kabui edilebileceği literatürde bildirilmektedir (Wang 1971, Subrahmaniam and Subrahmaniam 1973; Tiku and Singh 1981, Hsiung and Olejnik 1996, Ware 1997. Cliff 1997, Gorham 1998,
Zar 1999). Bu durumda, tekrarlanan ölçümlu varyans analizi tekniginde butun grup sayısi-korelasyon katsayıs!ornek genișliği kombinasyonlannda L. Tip hata olasilikiarinin \%5 olarak gerçekleştiği Çizelge 2' de góralmektedir.

Bu sonuçlara göre, yapilan simülasyon çalışmasinda ele alınan ornek genişlikleri-grup sayısi-korelasyon katsayısı kombinasyonlarına, basit varyans analizi tekniği uygulandiğı zaman gerçekleşen en kuçük I. Tip hata yapma olasiliğınin degeri $0.00000(0.00)$, en bayagunan ise $0,05158(0,05)$, tekrarlanan ôlçúmí varyans analizi tekniğinde ise en Koçalk L. Tip hata yapma olasılığı $0,04774(0.05)$, en boyok I. Tip hata yapma olasıliğ ise $0,05229(0,05)$ olarak gerçekleşmiştir, Bu olasıliddarın genel ortalama ve standart sapmasi ise, basit varyans analizinde 0.01394 ve 0.01663 , tekrarlanan olçamia varyans analizinde $0,04999(0.05)$ ve $0.00071(0.00)$ olarak bulunmuştur. Bu degerler incelendiğinde ortalama I. Tip hata yapma olasılıklannin, başlangıçta belirlenen $\% 5$ seviyesine istatistik olarak tekrarlanan olçamla varyans analizinde eşit olduğu goroular. Ayrica standart sapmanın da çok küçok olmasi gerçekleşen hataların birbirine yakin olduğunun bir göstergesidir. Ancak basit varyans analizi tekniğinde I. Tip hata yapma olasilığının başlangıçta belirlenen değerinden oldukça farkli olduğu anlaşilmaktadir.

Bulunan bu sonuçlar doğrultusunda korelasyon yapisındaki değlsmmelerden tekrarlanan olçumlo varyans analizinin atkilenmediği sobylenebilir.

\section{Sonuç ve Öneriler}

Yapilan bu çalışma sonucunda, gruplardaki gözlem değerleri arasinda korelasyon olduğu durumlarda (gozlemlerin bağımlı olmasi halinde) tekrarianan olçamlö varyans analizi tekniğinin kullanilması gerektiği görülmektedir. Aksi taktirde başlangiçta belirtenen L. Tip hata yapma olasiliğı $(\alpha)$, gozlemler arasındaki korelasyonun artmasına bağlı olarak azalacaktır. Bu sonuç ise test hipotezinin gereğinden fazla kabul edilmesine yol açacaktir, Ayrica, gözlemler arasındaki korelasyon katsayısının sıfır olması halinde de (gozlemlerin bağımsız olmasi) tekrartanan ölçumlo varyans analizi tekniği ile basit varyans analizi tekniğinin I. Tip hatayı başlangıçta belirlenen \%5'lik seviyede tutma bakimindan ayni etkinliğe sahip olduklan da göralmasstor. Tekrarianan ólçamia varyans analizi tekniğinin bir sonucu olarak hesaplanacak hata kareler artalamasi (deneme hatasi), her zaman basit varyans analizi teiknigi ile hesaplanan hata kareler ortalamasından koçok olmaktadir. Deneme hatasının küçäk olması araștırmalarda oldukça onemli bir husustur.

Bu bakımdan, bağımh ve bağımsız gözlemierden olușturulan gruplarda, basit varyans anaiizi ve tekrarlanan óccoumló varyans analizi tekniklerine gore grup içi varyanslanı seyrinin nasıl olduğu yaninda uygulanan testlerin gúç değerierinin de ele alındiğı simulasyon çalışmasına gerek vardır. Böyle bir çalışma planlanmış ve yürutülume aşamasindadır. 
Cizaige 2. Simulasyon çalișmasinda Grup sayısı-Korelasyon katsayısı-Omek genişliğl kombirasyonianinda ANOVA ve TOVA sonuçianna gäre gerçekjeşen i. Tip hata yapma olasilikian

\begin{tabular}{|c|c|c|c|c|c|c|c|c|c|c|c|c|c|}
\hline \multirow{3}{*}{ Grup } & \multirow{3}{*}{ P } & \multicolumn{6}{|c|}{$\begin{array}{c}\text { Basit varyans analizinde junek genisliklerine gôre } \\
\text { gercektesen f. Tip hata olasiliktan }\end{array}$} & \multicolumn{6}{|c|}{$\begin{array}{c}\text { Tekrarlanan ölçümlo varyans analizinde ômek geniģ|liklerine } \\
\text { güre gerçekleșen I. Tip hata olasillkları }\end{array}$} \\
\hline & & & & & & & & & & & & & \\
\hline & & 5 & 10 & 15 & 20 & 25 & 30 & 5 & 10 & 15 & 20 & 25 & 30 \\
\hline \multirow{10}{*}{2} & 0.0 & 0.05158 & 0.04982 & 0.04988 & 0,04985 & 0,05061 & 10,05023 & 0.05036 & 004948 & 0,04944 & 0.04937 & 0.05029 & 0.05014 \\
\hline & 0,1 & 0.04079 & 0.04097 & 0,03955 & 0,03994 & 0.03957 & 0.03534 & 0.05079 & 005060 & 0.05014 & 0.04968 & 0,05024 & 0.04863 \\
\hline & 0.2 & 0.03371 & 0.03110 & 0,03029 & 0,02969 & 0,02984 & 0,02935 & 0.04962 & 0.04917 & 0,05075 & 0,04922 & 0.05041 & 0.04989 \\
\hline & 0,3 & 0.02641 & 0.02305 & 0,02149 & 0.01999 & 0.02030 & 0,02014 & 0.04978 & 0.05010 & 0,05039 & 0,05043 & 0.04978 & 0.04997 \\
\hline & 0.4 & 0.02005 & 0.01521 & 0.01813 & 0.01336 & 0.01304 & 0.01236 & 0,05010 & 0,04889 & 0,04858 & 0.05013 & 0.05087 & 0,04818 \\
\hline & 0.5 & 0,01416 & 0.00969 & $0.0 \mathrm{~d} 77 \mathrm{1}$ & 0,00709 & 0,00675 & 0.00706 & 0.05087 & 005001 & 0,04997 & 0.05060 & 0.04924 & \\
\hline & 0.8 & 0.00950 & 0.00525 & 0.00369 & 0.00357 & 0.00339 & 0.00290 & 0.05119 & 0.05017 & 0.05084 & 0.05035 & 0.05050 & 0.04997 \\
\hline & 0.7 & 0.00531 & 0.00197 & 0,00144 & 0,00106 & 0.00005 & 0,00075 & 004946 & 0,05006 & 0,04961 & 0.04958 & 0.05029 & 0.05073 \\
\hline & 0.8 & 0.00334 & 0.00050 & 0.00015 & 0.00020 & 0,00011 & 0,00008 & 004958 & 0.04961 & 0,05102 & 0.04993 & 0.04955 & 0.04974 \\
\hline & 0.9 & 0.00060 & 0.00004 & 0,00001 & 0.00000 & 0,00000 & 0.00000 & 0,05101 & 004963 & 0.04878 & 0.05034 & 0,05022 & 0.05200 \\
\hline \multirow{10}{*}{3} & 0.0 & 0.05093 & 0.04973 & 0.05068 & 0.05105 & 0,05024 & 0,05007 & 005115 & 0.05001 & 0.04970 & & 0.05040 & \\
\hline & 0.1 & 0.03933 & 0.03829 & 0.03658 & 0.03541 & 0,003620 & 0.03623 & 0,05030 & 005096 & 0,04962 & 0.04936 & 004973 & 0,04969 \\
\hline & 0.2 & 0.03034 & 0.02662 & 0,02559 & 0.02467 & 0.02480 & 0,02573 & 0.05054 & 0.04950 & 0,04982 & 0.04914 & 0.04927 & 0.05041 \\
\hline & 0.3 & 0.02291 & 0.01730 & 0.01702 & 0.01556 & 0.01642 & 0.01497 & 0.04961 & 0.04945 & 0.05074 & 0.04946 & 005220 & 0.05059 \\
\hline & 0.4 & 0.01540 & 0,01125 & 0.00922 & 0.00909 & 0.00867 & 0,00774 & 0,04972 & 0.05127 & 0,04970 & 0.05030 & 0.04935 & 0,04992 \\
\hline & 0.5 & 0.01077 & 0.00569 & 0.00526 & 0.00416 & 0.00380 & 0.00389 & 0.05012 & 0.04961 & 0.04979 & 0.04899 & 0.04943 & \\
\hline & 0.6 & 0.00632 & 0.00313 & 0,00212 & 0.00147 & $0,001 \propto 8$ & 0.00109 & 0.04987 & 005069 & 0.05079 & $0.0<937$ & 0.05044 & 0.04903 \\
\hline & 0.7 & 0.00340 & 0.00096 & 0.00051 & 0.00029 & 0.00016 & 0.00023 & 0.04843 & 0.04978 & 0.05061 & 0.04900 & 0.04951 & 0.0 \\
\hline & 0.8 & 0.00144 & 0.00026 & 0,00003 & 0,00005 & 0,00001 & 0,00000 & 0.04969 & 005062 & 0,05029 & 0,05036 & 0.04976 & 0.04896 \\
\hline & 0.8 & 0,00041 & 0.00000 & 0.00000 & 0.00000 & 0.00000 & 0,00000 & 0,04991 & 004980 & 0.05015 & 0.05028 & 0.04923 & 0.0 \\
\hline & 0.0 & 0.04978 & 0.05078 & 0,04999 & 0.04958 & 0,05062 & 0.04812 & 0.05074 & 0.05051 & 0.05010 & 0,04938 & 0.05068 & \\
\hline & 0,1 & 0,03668 & 0.03722 & 0.03489 & 0.03443 & 0.03486 & 0.03439 & 005010 & & 0.05017 & 0.05038 & 0.04969 & $0 . C$ \\
\hline & 0.2 & 0.02728 & 0.02377 & 0,02254 & 0.02199 & 0,02201 & 0,02159 & 0,05005 & 0.04944 & 0.04965 & 0,04938 & 0,04954 & \\
\hline & 0.3 & 0.01986 & 001516 & 0.01359 & 0.01283 & 0.01196 & 0.01202 & 0.05082 & 0.05055 & 0,04964 & 0.04942 & 0.04925 & 0.04952 \\
\hline & 0.4 & 0.01349 & 0.00923 & 0,00748 & 0,00681 & 0.00626 & 0.00504 & 0.04964 & 0.04986 & 0.04972 & 0.05049 & 0.05111 & 0.05088 \\
\hline & 0.5 & 0.00886 & 000411 & 0.00360 & 0.00303 & 0.00268 & 0.00233 & 0.051 .59 & 0.04893 & 0,05072 & 0.04989 & 0,05089 & 0.05049 \\
\hline & 0.6 & 0,00510 & 0.00180 & 0 D01 18 & 0.00081 & & 0.00044 & 0,04922 & 0.04990 & 0.05188 & 982 & 0.04928 & D. \\
\hline & 0.7 & 0.00273 & 000070 & 0.00032 & 0.00017 & 0,00004 & 0,00010 & 0.05034 & 0,04974 & 0,05048 & 0.04962 & 0.05081 & 109 \\
\hline & 0.8 & 00118 & 0.00014 & 0,00000 & 0.00002 & 0,00001 & 0.00000 & 0.05000 & 005031 & 0,05026 & 0.05070 & 005034 & \\
\hline & 0.9 & 00031 & 0.00000 & 0.00000 & 0,00000 & 0,00000 & 0,00000 & 0.05029 & 0.04964 & 0,04921 & 0,04998 & 005132 & 0.04983 \\
\hline & 0.0 & 0.05023 & 0.05021 & 0.05078 & 0.05064 & 0.04885 & 0.04916 & 0.04932 & 0.05027 & 0.05144 & 0.05065 & 0.04905 & 0.04908 \\
\hline & 0.1 & 0.03614 & 0.03357 & 0,03308 & 0.03268 & 0.03390 & 0.03249 & 005016 & & 0.04969 & 0.05003 & 0,05002 & \\
\hline & 0,2 & 0.02534 & 0.02244 & 0.02017 & 0.02023 & 0.02020 & 0.01968 & 0.05034 & 0.05006 & 0.04958 & 0.04946 & 0.05035 & 0.05083 \\
\hline & 0,3 & 0.01722 & 0.01302 & 0.01121 & 0.01091 & 0,01089 & 0,00987 & 0.05105 & 0.04936 & 0,04987 & 0.05039 & 0,04949 & 0.04902 \\
\hline & 0.4 & 0.01155 & 0.00707 & 0.00597 & 0.00534 & 0,00476 & 0.00426 & 0,05058 & 0,04951 & 0.05035 & 0.04921 & 0.04905 & 0.04955 \\
\hline & 0.5 & 0.00765 & 0.00335 & 0.00248 & 0,00204 & $0.001 \approx$ & 0.00154 & 0.04999 & 0.05048 & 0.04899 & 0.05072 & 0.05095 & 0.04897 \\
\hline & 0.6 & 0.00442 & $0.0013 \alpha$ & 0.00081 & 0,00059 & 0.00041 & 0,00026 & 0.05039 & 0.05065 & 0.05009 & 0.05123 & 0.04898 & 0.04976 \\
\hline & 0.7 & 0.00213 & 000039 & 0.00014 & 0.00014 & 0,00002 & 0.00002 & 0,05038 & 0.05053 & 0,04963 & 0.05018 & 0.04987 & 0.05002 \\
\hline & 0.8 & 0.00100 & 0.00008 & 0.00003 & 0.00000 & 0,00000 & 0.00001 & 0.05169 & 0.05030 & 0.04999 & 0,04927 & 0.05053 & 0,05028 \\
\hline & 0.9 & 00015 & 0,00000 & 0.00000 & 0.00000 & 0.00000 & 0,00000 & 0,04935 & 0.04905 & 0,05026 & 0,04803 & 0.05085 & \\
\hline \multirow{10}{*}{10} & 0,0 & 0.05064 & 0.04958 & 0,05024 & 0.04966 & 0.04941 & 0.05042 & 0.05083 & 004944 & 0.05034 & 0.04994 & 0,04932 & 0,05011 \\
\hline & 0.1 & 0.03199 & 0.02855 & 0.02827 & 0.02707 & 0.02794 & 0,02727 & 0.04996 & 0.04868 & 0.04367 & 0.04917 & 0.05022 & 0.05082 \\
\hline & 0.2 & 0.01902 & 0.01660 & 0.01500 & 0.01367 & 0.01375 & 0.01346 & 0.04887 & 0.05037 & 0.05135 & 0.04964 & 0.04907 & 0.05117 \\
\hline & 0.3 & 0.01206 & 0.00832 & 0,00639 & 0.00622 & 0,00595 & 0.00564 & 0.04961 & 0.05003 & 0,04996 & 0,05040 & 0.05081 & 0.05024 \\
\hline & 0.4 & 0.00769 & 0.00382 & 0,00249 & 0.00197 & 0.00168 & 0.00146 & 0.05103 & 0.05060 & 0.04963 & 0.05020 & 0.04986 & 0.04973 \\
\hline & 0.5 & 0.00448 & 0.00162 & 0,00075 & 0.00053 & 0,00043 & 0.00038 & 0.04979 & 0.05093 & 0.04914 & 0,04915 & 0.05053 & 0.04933 \\
\hline & 0,6 & 0.00216 & 0.00048 & 0.00020 & 0.00007 & 0.00006 & 0.00005 & 0.05001 & 0.05036 & 0.05022 & 0.05056 & 0.04993 & 0.04979 \\
\hline & 0.7 & 0.00133 & 0.00016 & 0.00004 & 0.00001 & 0,00000 & 0,00000 & 004988 & 004959 & 0,04984 & 0.04956 & 0,04922 & 0.05043 \\
\hline & 0.8 & 0.00047 & 0.00001 & 0.00000 & 0.00000 & 0.00000 & 0.00000 & 0.05056 & 0.05021 & 0,04832 & 0,05025 & 0.05030 & 0.04830 \\
\hline & 0,9 & 0.00007 & 0.00000 & 0.00000 & 0.00000 & 0.00000 & 0.00000 & 0.05054 & 0.04975 & 0.04957 & 0.05088 & 0.04994 & 0.05035 \\
\hline
\end{tabular}


BAŞPINAR, E., F. GÜRBÜZ ve H. ÇAMDEVIREN, "Varyans analizi ve tekrarlanan ölçümlü analiz tekniklerinin I. Tip hata bakımından karşılaştırııması"

\section{Kaynaklar}

Cliff, N. 1997. Robustness and Power of D Statistics in Comparison to t For Paired Data. DAI-B 57/07, s. 4774.

Çamdeviren, H. 1995. Tekrarlanan Ölçümlü Deneme Düzenleri. Yäksek Lisans Tezi. A.Ü.Fen Bilimleri Enstitüsú. Basıımamış. $125 \mathrm{~S}$.

Düzgüneş, O., T. Kesici, O. Kavuncu ve F. Gürbüz. 1985. Araștırma ve Deneme Metodları (istatistik II). A.U..Z.F. Yayınları. Yayın No: 445. $452 \mathrm{~S}$.

Gorham, J. L. 1998. The Effects on Type I Error Rate and Power of Selected Competitors to the ANOVA $F$ Test in Randomized Block Design Under Non-Normality and Variance Heterogeneity. DAl-B 58/12, s. 6650 .

Gürbüz, F. E. Öğüş, H. Çamdeviren, E. A. Kanık ve B.Tekindal. 1999. Tek Faktörlü Tekrarlanan Ölçümlü Deneme Dúzeni. 4. Ulusal Biyoistatistik Kongresi. 23-24 Eylül Ankara.

Hsiung, T. H. and S. Olejnik, 1996. Type I Error Rates and Statistical Power for the James $2^{\text {nd }}$-Order Test and the Univariate F-Test in 2-Way Fixed Effects ANOVA Models Under Heteroscedasticity and/or Nonnormality. Jour. of Experimental Education, 65(1) 57-71.

Kurita, K. 1996. The Biasing Effects of Violating the Independence Assumption Upon the Power of $t$-Test. Jap.Jour. of Educ. Psyc. 44(2), pp 234-242.
Sokal, R. R. and F. J.Rohlf, 1995. Biometry. The Principles and Practice of Statistics in Biological Research. Third Ed. W.H.Freeman and Co. New York, 887 S.

Subrahmaniam, K. and K. Subrahmaniam, 1973. On the Multivariate Behrens-Fisher Problem. Biometrica, (60) 107111

Tiku, M. L. and M. Singh, 1981. Robust Test For Means When Population Variances are Unequal. Commun. Statist.-Ther. Math. $A 10(20)$ 2057-2071.

Wang, Y. Y. 1971. Probabilities of the Type I Errors of the Welch Test for the Behrens-Fisher Problem. Jour. of the American Statist. Assoc. 66(335) 605-608.

Ware, W. B. 1997. Detecting Departures From Normality: A Monte Carlo Simulation of a New Omnibus Test Based on Moments. DAI-A 58/04, s. 1196.

Winer, B. J. 1971. Statistical Principles in Experimental Design. Sec.Ed. McGraw-Hill Book Co., New York-USA, 907 P.

Zar, J. H. 1999. Biostatistical Analysis. Fourth Ed. Prentice Hall Inc., Upper Saddle River, New Jersey, USA. $663 \mathrm{~S}$. 